\title{
Isomerization of glucose into fructose with homogenous amine-type base catalysts: amine structure, chain length, and kinetics
}

\author{
Libo Zhang ${ }^{1 *}$, Bailian Deng ${ }^{1}$, Nan $\mathrm{Li}^{1}$ and Hong Zhong ${ }^{2^{*}}$
}

\begin{abstract}
Three homogeneous organosilanes amine and aliphatic primary amine were used as amine catalysts to evaluate their catalytic activity and kinetic towards glucose isomerization. Catalysts structure (primary, secondary, tertiary amine), terminal groups and alkyl chain length were investigated and compared elaborately. Result showed organosilanes tertiary amine behaved the best and amine generated $\mathrm{OH}^{-}$and amine itself contributed the isomerization reaction. The generated acidic by-product not only decreased fructose selectivity but also affected glucose conversion kinetic. The effect of siloxane (-Si-O- $\left.\mathrm{CH}_{3}\right)$ substituent with methyl $\left(-\mathrm{CH}_{3}\right)$ can be insignificant, but it provided guiding significance for selecting amine-type homogeneous or grafted amine catalysts for glucose isomerization reaction. Longer alkyl chain resulted in lower glucose conversion because of the alkyl chain curls that would weaken the amine catalytic effect and hydration ability. Catalyst loading and initial glucose concentration investigations further showed that amine would effectively catalyze the isomerization reaction under varied operational conditions. This work will provide more details about organic amine catalysts on glucose isomerization into fructose and promote synthesis of platform chemicals in the applications of biorenewable chemicals and fuel.
\end{abstract}

Keywords: Organosilanes, Aliphatic primary amine, Amine structure, Isomerization kinetic, Terminal substitution, Alkyl chain length, Operational conditions

\section{Introduction}

With gradual depletion of traditional fossil resources, several promising biomass-derived products have been identified to be attractive due to the advantages of them being renewable, globally available, and environmentally friendly (Shen et al. 2019). Biomass feedback is of $75 \%$ carbohydrates with an empirical formula of $\mathrm{C}_{6} \mathrm{H}_{12} \mathrm{O}_{6}$, which is produced by sunlight photosynthesis with $\mathrm{CO}_{2}$ and $\mathrm{H}_{2} \mathrm{O}$ (Mika et al. 2018). Therefore, the conversion of carbohydrates into various chemicals and biofuels is one of the most important tactics in bioeconomy chain according to the idea of "biorefinery concept" (Mika et al. 2018). Among those biomass-derived carbohydrates,

\footnotetext{
*Correspondence: zhanglibo@cupk.edu.cn; hzhong@polyu.edu.hk 1 State Key Laboratory of Heavy Oil Processing, College of Engineering, China University of Petroleum-Beijing at Karamay, Karamay 834000, China ${ }^{2}$ Renewable Energy Research Group (RERG), Department of Building Services Engineering, The Hong Kong Polytechnic University, Hong Kong, China
}

fructose is a crucial feedstock (Li et al. 2017c). Except as a well-known sweetener that alternates as conventional table sugar (sucrose) (Yabushita et al. 2019), fructose could also be as a raw material for the production of 5-hydroxymethylfurfural (5-HMF) (Du et al. 2019; Morales-Leal et al. 2019; Shaikh et al. 2018). 5-HMF is a popular chemical that can be further processed into 2,5-furandicarboxylic acid (FDCA), which is a renewable substitute of petroleum-based terephthalic acid in polyester (Gorbanev et al. 2009; Zhang and Deng 2015). In some similar manners, fructose acts as an intermediate to synthesise some other platform compounds, such as levulinic acid and its esters, alkyl fructosides and 5-ethoxymethylfurfural as shown in Fig. 1 (Corma et al. 2007; Lam and Luong 2014; Li et al. 2016, 2017b, c).

Fructose is the product of glucose isomerization. Recently, immobilized enzymes have been used as biocatalyst for industrial fructose production, and a fructose yield of $42 \%$ was obtained (Lee and Hong 2000; Li 
<smiles>OC[C@H]1OC(O)[C@H](O)[C@@H](O)[C@@H]1O</smiles>

Glucose<smiles>[R]OC1(CO)O[C@H](CO)[C@@H](O)[C@H]1O</smiles>

Alkyl fructosides
High Frucose Corn Syrup (HFCS)

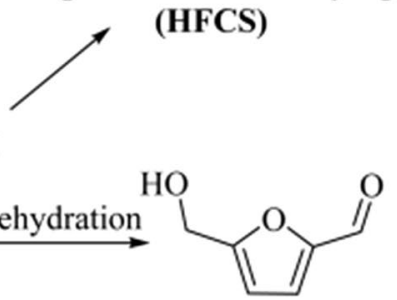

Isomerisation

5-Hydroxymethlyfurfural

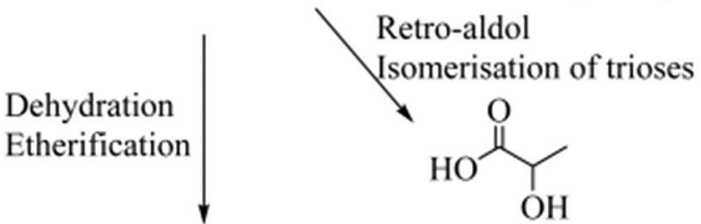

Lactic acid<smiles>[R]OCc1ccc(C=O)o1</smiles>

5-Alkoxymethylfurfural ethers

Fig. 1 Representative products derived from fructose (Li et al. 2017c)

et al. 2017a). However, the biological catalyst suffers from various drawbacks, such as the poor stability, high cost, needed by buffers and irreversible deactivation (Lee and Hong 2000; Shen et al. 2019; Yang et al. 2016). Meanwhile, the glucose isomerase is vulnerable to the surroundings (temperature, $\mathrm{pH}$ and feed purity, etc.) that strict control over operating conditions is required. Therefore, chemical catalytic process for glucose isomerization into fructose is an alternative approach of enzyme process fructose production ( $\mathrm{Li}$ et al. 2017c).

Seminal work discovered that glucose isomerization could be catalyzed by the Lewis acidic zeolite Sn-Beta (Moliner et al. 2010). Despite of the existence of Sn active sites' leaching, this work has sparked interest in searching chemical catalysts for glucose isomerization (Olson et al. 2019). Later, several intriguing chemical catalysts for this reaction have been investigated, including homogeneous and heterogeneous Lewis acids, inorganic Brønsted bases (Carraher et al. 2015), organic bases (Liu et al. 2014) and so on.

Among those chemical catalysts, amine-type organic bases catalysts are intriguing for their high tunability and no cation-ketose complex forming according to Lobry de Bruyn-Alberda van Ekenstein mechanism (de Bruijn et al. 1986; Liu et al. 2014; Yang and Montgomery 1996) and broader range of $\mathrm{p} K \mathrm{a}$ (Liu et al. 2014). Besides, amines could easily be found in a variety of natural products such as food and drugs. In addition, their availability and low toxicity make them ideal candidates to produce fructose for food, chemical, and fuel applications (Liu et al. 2014). Chemical structure (acyclic vs. cyclic amine), nature of the amine groups (primary, secondary, tertiary amine), and $\mathrm{p} K \mathrm{a}$ are the major factors that affect amine catalyst activity. In previous study, morpholine, piperazine, ethylenediamine, triethylamine, piperidine and pyrrolidine were selected and tested to compare their catalytic activity towards glucose isomerization into fructose (Liu et al. 2014). Yield of 32\% with $63 \%$ fructose selectivity was reached after $20 \mathrm{~min}$ at $100{ }^{\circ} \mathrm{C}$ (Liu et al. 2014), which with the similar performance as state of the art Lewis acid catalysts (Souza et al. 2012). To improve catalysts' stability, PS particles or $\mathrm{Fe}_{3} \mathrm{O}_{4}$ supported 1-(3-aminopropyl) imidazole (API), tetramethylguanidine (TMG) and 1,5,7-triazabicyclo[4.4.0]dec-5-ene (TBD) were also developed (Yang et al. 2015). Higher glucose-to-fructose yield and selectivity were achieved in water under a wide range of temperature with excellent catalysts stability and reusability (Yang et al. 2015). Besides, tertiary amine functionalized SBA-15 was created and acted as heterogeneous catalytic materials for glucose-to-fructose isomerization, alkyl linker length of the amine tether was investigated (Deshpande et al. 
2017). Results revealed that decreasing the length of the active site tether could improve the catalyst performance significantly (Deshpande et al. 2017). Most recently, the impact of tertiary amines alkyl substituents structure on their catalytic performance for the isomerization of glucose to fructose was studied (Deshpande et al. 2019). Results demonstrated that amines with less bulky substituent achieved higher glucose conversion (Deshpande et al. 2019).

Although some efforts have been taken to investigate the relationship between amine structure and their performance in glucose isomerization reaction, the role of the amine in glucose isomerization has received limited understanding because of their wide variety. More detailed understanding of the catalytic process was desired (Liu et al. 2014). Especially the overall influence of amine substituents is not fully understood. In this present work, first, three homogeneous amine type organosilanes amine (primary, secondary, and tertiary amine) were chosen as catalysts to screen their catalytic activity and catalytic kinetic towards glucose isomerization. Second, the substituents of siloxane $\left(-\mathrm{Si}-\mathrm{O}-\mathrm{CH}_{3}\right)$ group with methyl $\left(-\mathrm{CH}_{3}\right)$ were performed and their activity was compared elaborately. Finally, three kinds of aliphatic primary amine, which with 2, 6 and 8 alkyl chains, were adopted as amine catalysts to directly investigate the influence of chain length on glucose isomerization. Meanwhile, catalysts loading and glucose feed concentration were illustrated. This work will provide more details about amine catalysts on glucose isomerization into fructose and will promote synthesis of platform chemicals in the biorenewable chemicals and fuel applications.

\section{Experimental}

\section{Materials}

Deionized water (DI water, $18.25 \mathrm{M} \Omega \mathrm{cm}$ ) was prepared using a water purification system (Water Purifier, WPUP-UV-20, Sichuan Water Technology Development Co. Ltd, China). Fructose and glucose (Alfa Aesar Tianjin China, 99\%) were used as received. Structures and their abbreviations of the three homogeneous amine type organosilanes and aliphatic primary amine with 2, 6 and 8 alkyl chain are shown in Figs. 2 and 6. All other chemicals are of analytical grade or higher and were used without further treatment.

\section{Reaction testing}

The glucose isomerization into fructose reaction was performed in a $10 \mathrm{~mL}$ thick-walled glass reactor made by Alltech. An oil bath was used to heat the reactor rapidly to the desired temperature. In a typical experiment, a certain amount of glucose, amine-type catalyst, and $5 \mathrm{~mL}$ deionized water were added to the glass reactor. A triangular magnet stir bar (Fisher Scientific) was also added to allow for adequate agitation. After a certain period, the reaction was quenched with flowing water.

\section{Products analysis}

After each step of reaction finished, the resulting solution was analyzed by HPLC without any pretreatment. HPLC was equipped with an Aminex HPX-87H column and refractive index detectors. $5 \mathrm{mM} \mathrm{H}_{2} \mathrm{SO}_{4}$ was used as the mobile phase at a flow rate of $0.6 \mathrm{~mL} / \mathrm{min}$ and the column temperature was maintained at $60{ }^{\circ} \mathrm{C}$. According to our previous work ( $\mathrm{Xu}$ et al. 2019), the mannose yield

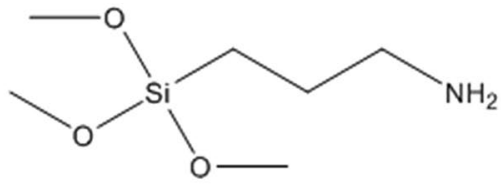

3-(trimethoxysilyl)propan-1-amine (APTES)

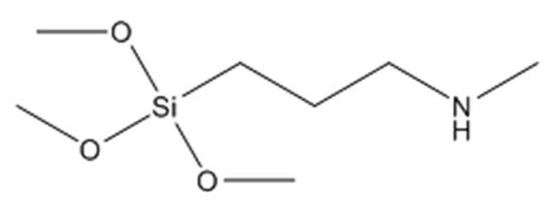

$N$-methyl-3-(trimethoxysilyl)propan-1-amine (APTMS)

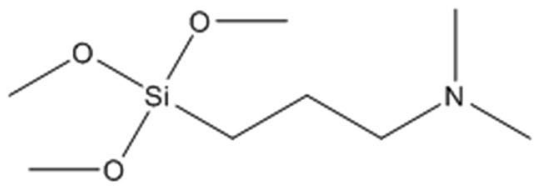

$N, N$-dimethyl-3-(trimethoxysilyl)propan-1-amine (DMASi)

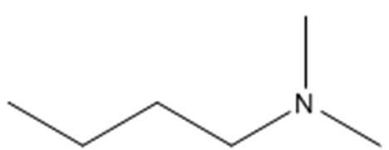

N,N-dimethylbutylamine $\left(\mathrm{BuNMe}_{2}\right)$

Fig. 2 The structures of organosilanes amine catalysts 
from glucose catalyzed by organosilanes amines was $<1 \%$, so the mannose could be negligible in this work.

$$
\begin{aligned}
\text { Conversion of glucose }(\%)= & \frac{\text { moles of glucose reacted }}{\text { moles of glucose supplied }} \\
& \times 100
\end{aligned}
$$

Yield of fructose $(\%)=\frac{\text { moles of fructose formed }}{\text { moles of glucose supplied }} \times 100$

Selectivity for fructose $(\%)=\frac{\text { moles of fructose formed }}{\text { moles of glucose reacted }}$

$$
\times 100
$$

\section{Results and discussion}

\section{Comparation of primary, secondary and tertiary amine}

Some organic bases have been investigated as homogeneous catalysts for the isomerization of glucose to fructose in water (Carraher et al. 2015; Liu et al. 2014). However, homogeneous organosilanes amines have been not involved. Initial catalytic testing focused on determining the effect of the amine structures for homogeneous amines on fructose yield and selectivity. Thus, organosilanes amines with different chemical structures (primary, secondary, and tertiary amine) were selected. Effects of reaction conditions (time, temperature) on fructose yields and selectivity are shown in Fig. 3.

Under designed experiment conditions, a 34\% fructose yield and $75 \%$ selectivity was achieved with DMASi (with tertiary amine) at $110{ }^{\circ} \mathrm{C}$ for $60 \mathrm{~min}$. This result is superior to previous reports, which obtained a $32 \%$ fructose yield and 63\% selectivity (Liu et al. 2014), which indicates the organosilanes amines are more active for fructose production. In terms of fructose yield, DMASi (with tertiary amine) and APTMS (with secondary amine) exhibit similarly and both are higher than APTES with primary amine. While the fructose selectivity for DAMSi is around $80 \%$ that is far higher than APTES $(\sim 70 \%)$ and APTMS $(\sim 55 \%)$ for all the screened temperature. This indicates that for organosilanes amines, the tertiary
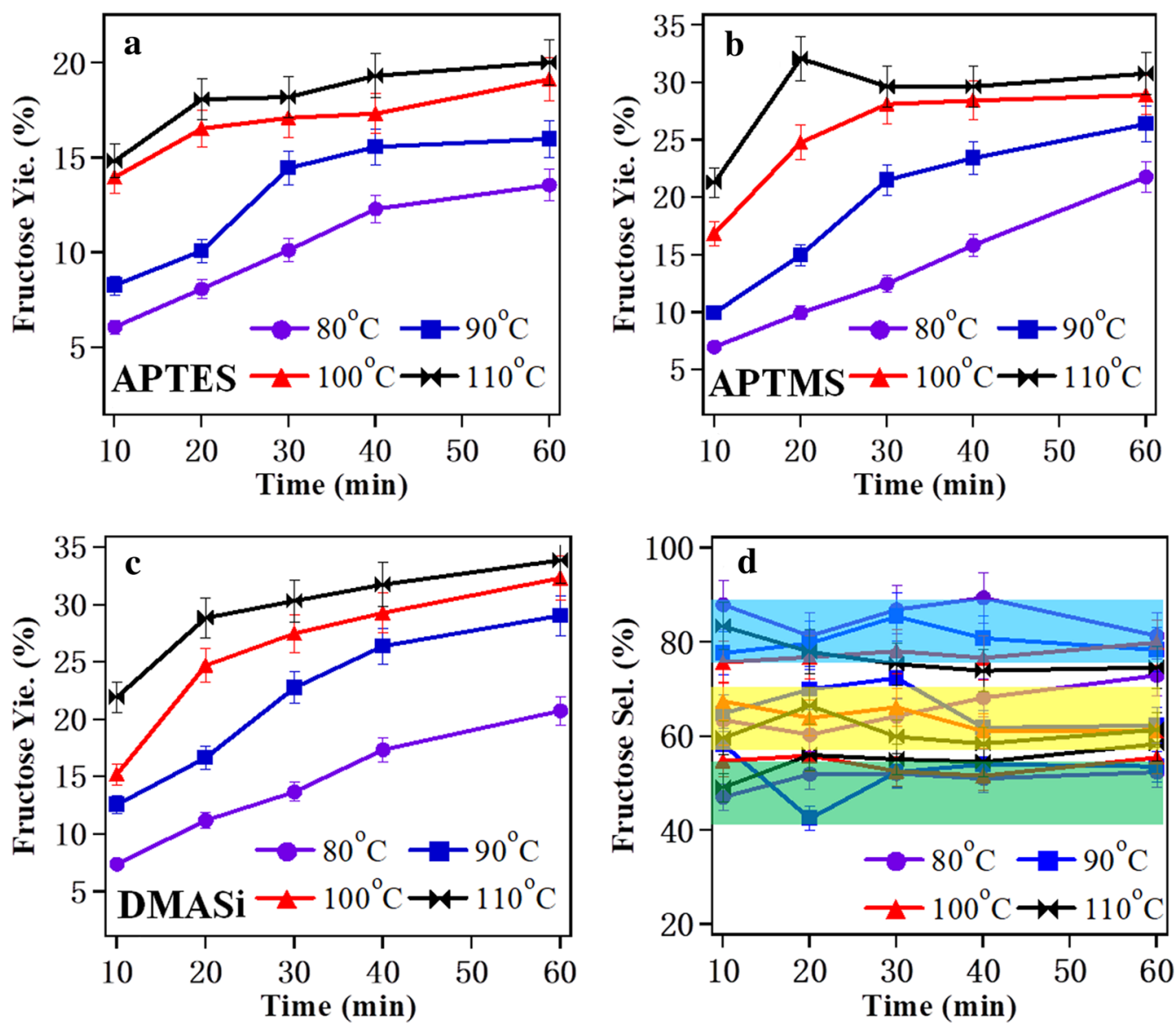

Fig. 3 Fructose yield versus time profiles for organosilanes amines. a APTES, b APTMS and c DMASi. Blue, yellow and green checkers present

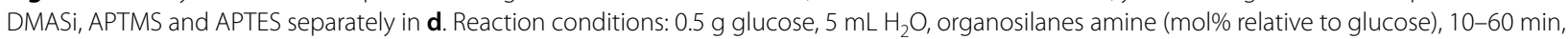
$80-110^{\circ} \mathrm{C}$ 
amine is a higher efficient isomerization catalyst for glucose-to-fructose isomerization, which is consent with some other reports (Deshpande et al. 2019; Yang et al. 2015).

Previous research demonstrated that amine-generated hydroxide ion $\left(\mathrm{OH}^{-}\right)$catalyzes glucose isomerization reaction (Carraher et al. 2015). Hence the $\mathrm{p} K a$ for amine is regarded as a decided factor in glucose isomerization. Interaction between nitrogen atom and $\mathrm{H}_{2} \mathrm{O}$ could affect its $\mathrm{OH}^{-}$generation ability (Liu et al. 2014). The lone electron pair of nitrogen held in a $\mathrm{sp}^{3}$ orbital is much easier to protonate than the one held in a $\mathrm{sp}^{2}$ or sp orbital (Liu et al. 2014; Yang et al. 2015). Besides, an NMR study confirmed that triethylamine did not participate in the Maillard reaction, which explained the tertiary amine performed better in glucose isomerization catalytic reaction (Liu et al. 2014). Recently, the contribution of the amine itself is emphasized, and current thinking is that the role of the amine itself is more important than the generated $\mathrm{OH}^{-}$. However, it is hard to distinguish the contribution of amine itself and its generated $\mathrm{OH}^{-}$. While, an indisputable fact is that amine with tertiary amine resulted in the higher fructose selectivity than primary and secondary amine. In this study, the $\mathrm{p} K \mathrm{a}$ values of the three adopted organosilanes amines are close, while their glucose catalytic effects are obviously diverse, so the role of amine itself is considered as more important in organosilanes. According to the proposed glucose isomerization mechanism (Liu et al. 2014; Yang et al. 2015), trimethylamine participated in the isomerization reaction but not in side reactions that led higher fructose selectivity than primary amine and secondary amine. Surely, deeper investigation is needed for further correlating the structural properties and catalytic performance for the amines.

\section{Kinetics of glucose conversion}

To explain the observed temperature effect and gain more insight on the glucose isomerization with organosilanes amines, the kinetics analysis and rate-constant fitting were estimated. First-order rate reaction was assumed and the reaction rate could be expressed as follows (Carraher et al. 2015):

$$
\ln \left(\left[[\mathrm{Glu}]_{t}\right] /[\mathrm{Glu}]_{0}\right)=-k t
$$

where $[\mathrm{Glu}]_{t}=$ glucose concentration at time $\mathrm{t}$ with unit of $\mathrm{mol} / \mathrm{L},[\mathrm{Glu}]_{0}=$ initial glucose concentration, $k=$ observed rate constant, and $t$ stands for time in seconds. A linear correlation between $\ln \left(\left[[\mathrm{Glu}]_{t}\right]\right)$ and reaction time $t$ was plotted. The $k$ obtained under different temperature was obtained. The results are shown in Fig. 4 and Table 1 respectively.
As shown in Fig. 4, when the adopted temperature is lower, the First-order rate reaction assumption fits the data points better. While at high temperature, the experimental points deviate from the kinetic model seriously. This can be explained by the fact that the higher the temperature, the more by-products produced, leading the selectivity of fructose to be lower as demonstrated in Fig. 3d. The color of the solution after the reaction turned to brown, which is similar to previous reports (Liu et al. 2014). Those color by-products have been mainly assigned to the 1,2-enediol intermediate, which is acidic (Kim and Lee 2008; Liu et al. 2014). The acidic by-products hindered the activity of bases in turn that resulted lower rate constant at higher temperature as shown in Table 1 . The generated acidic by-products not only decreased fructose selectivity but also reduced glucose conversion kinetic. Thus, the rate constants for $100{ }^{\circ} \mathrm{C}$ and $110{ }^{\circ} \mathrm{C}$ are lower than $80{ }^{\circ} \mathrm{C}$ and $90^{\circ} \mathrm{C}$. Those acidic by-products can be removed with commercially activated carbon as reported (Liu et al. 2014). So the separation of targeted fructose is not difficult.

\section{Effects of terminal groups}

Noteworthy structural feature for the three organosilanes amines is their end group of $-\mathrm{Si}-\mathrm{O}-\mathrm{CH}_{3}$. As well known, the $-\mathrm{Si}-\mathrm{O}-\mathrm{CH}_{3}$ could undergo hydrolysis and form $\mathrm{Si}-\mathrm{O}$ network. While, to our knowledge, whether $\mathrm{Si}-\mathrm{O}$ network can affect the glucose isomerization to a certain degree has not been investigated before. Although, the tertiary amine interacting with the surface of silica (also mainly $\mathrm{Si}-\mathrm{O}$ network) has been reported (Deshpande et al. 2019), whereas whether the prepared silica (SBA15) have different behavior compared with the hydrolysis in situ-formed $\mathrm{Si}-\mathrm{O}$ network is not clear. In this study, direct substituent of siloxane $\left(-\mathrm{Si}-\mathrm{O}-\mathrm{CH}_{3}\right.$ in $\left.\mathrm{DMASi}\right)$ with methyl $\left(-\mathrm{CH}_{3}\right.$ in $\left.\mathrm{BuNMe}_{2}\right)$ was performed and their activity was compared elaborately under $100{ }^{\circ} \mathrm{C}$ and $110{ }^{\circ} \mathrm{C}$. The results are shown in Fig. 5.

It was observed that for DMASi and $\mathrm{BuNMe}_{2}$ at 100 and $110{ }^{\circ} \mathrm{C}$, taken the experimental bias into account, the glucose conversion and fructose selectivity followed almost identical variation trend. A $40 \%$ glucose conversion with $75 \%$ fructose selectivity could reach, which is close to the reaction thermodynamic equilibrium in $\mathrm{H}_{2} \mathrm{O}$ (Moliner et al. 2010). This result demonstrates that the considered in situ hydrolysis effect of $-\mathrm{Si}-\mathrm{O}-\mathrm{CH}_{3}$ group could be negligible in the present experimental conditions. Although no different performance is observed, this result may also have guided significance for selecting amine-type homogeneous or grafted amine catalysts for glucose isomerization into fructose reaction. 

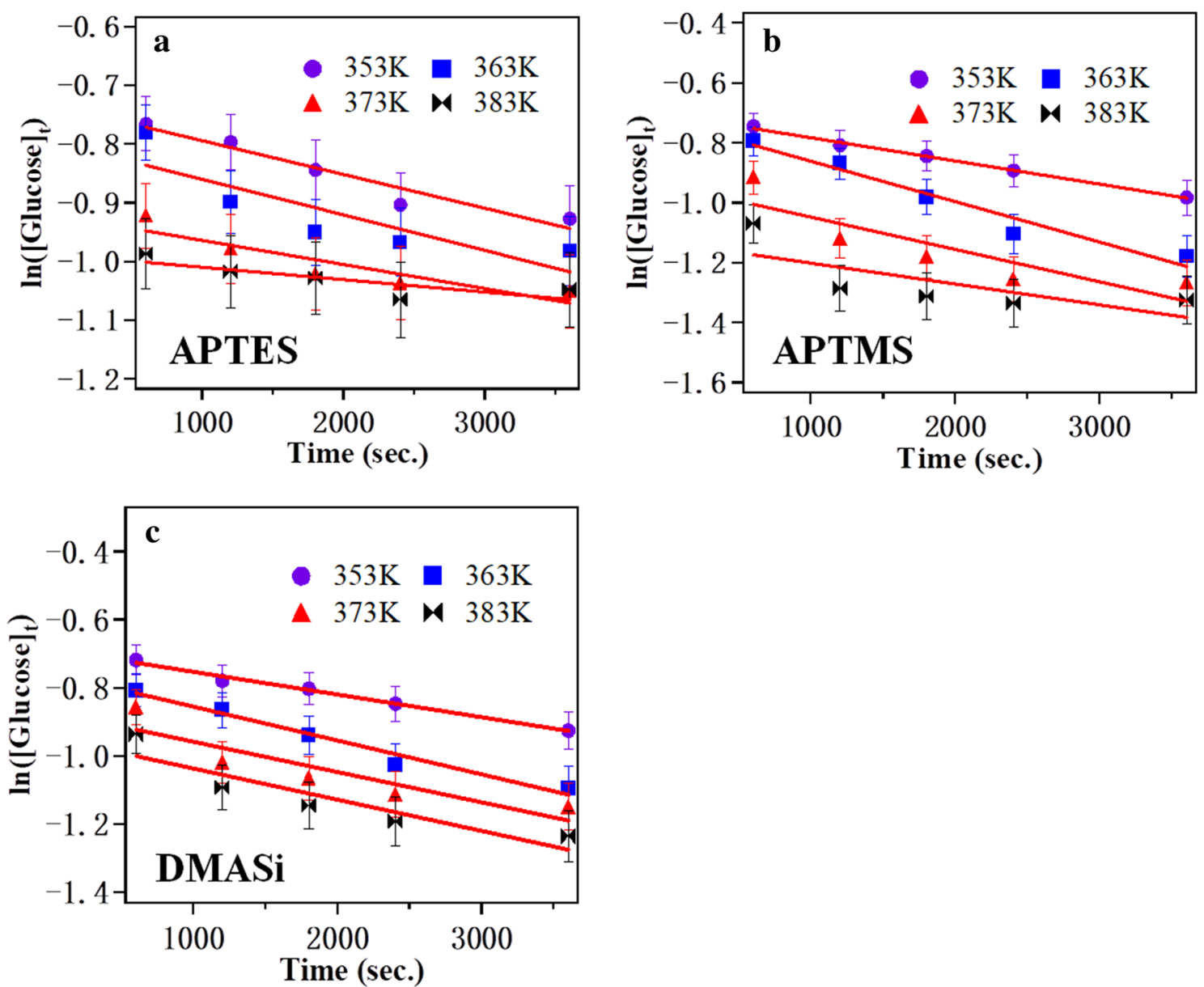

Fig. 4 Fitting of glucose concentrations as a function of time under different temperature for a APTES, b APTMS and $\mathbf{c}$ DMASi

Table 1 Fitted rate constants for APTES, APTMS and DMASi in glucose isomerization

\begin{tabular}{|c|c|c|c|c|}
\hline Catalysts & $\begin{array}{l}k_{80^{\circ} \mathrm{c}} \times 10^{-5} \\
\left(\mathrm{~s}^{-1}\right)\end{array}$ & $\begin{array}{l}k_{90}{ }^{\circ} \mathrm{c} \times 10^{-5} \\
\left(\mathrm{~s}^{-1}\right)\end{array}$ & $\begin{array}{l}k_{100^{\circ} \mathrm{C}} \times 10^{-5} \\
\left(\mathrm{~s}^{-1}\right)\end{array}$ & $\begin{array}{l}k_{110^{\circ} \mathrm{C}} \times 10^{-5} \\
\left(\mathrm{~s}^{-1}\right)\end{array}$ \\
\hline APTES & 5.74 & 6.05 & 4.10 & 2.12 \\
\hline APTMS & 7.75 & 13.48 & 10.80 & 6.94 \\
\hline DMASi & 6.62 & 9.93 & 8.90 & 9.17 \\
\hline
\end{tabular}

\section{Effects of chain length and experimental parameters}

As mentioned, the impact of alkyl substituent structure of amines on their catalytic performance for the glucoseto-fructose isomerization is obvious (Deshpande et al. 2019). The steric bulk of substituent was considered as a major factor that affected glucose isomerization catalytic activity (Deshpande et al. 2019; Liu et al. 2014). While more direct evidence is limited. In this part, three kinds of aliphatic primary amine with 2, 6 and 8 alkyl chain (as shown in Fig. 6), which have particular pronounced structure difference, were adopted as amine catalysts to investigate the effect of alkyl chain length on glucose isomerization into fructose reaction. The result is shown in Table 2.

Table 2 shows that when adopting aliphatic primary amine, $\sim 61$ to $\sim 70 \%$ fructose selectivity could be reached, which is close to APTES under the $110{ }^{\circ} \mathrm{C}$ as illustrated in Fig. 3d. This result shows for primary amine, fructose selectivity is not sensitive to their substituents structure. From organosilanes primary amine (APTES) to aliphatic primary amines, under the same temperature, the close fructose selectivity could be reached. Thus, it can be seen the importance of reaction temperature in glucose isomerization that impacts the fructose selectivity.

Another obvious phenomenon is when the alkyl chain of aliphatic primary amine is 2 and 6 (ethylamine and hexylamine), their catalytic glucose isomerization performance is similar with $\sim 40 \%$ glucose conversion and $\sim 61 \%$ fructose selectivity. While when the alkyl chain added to 

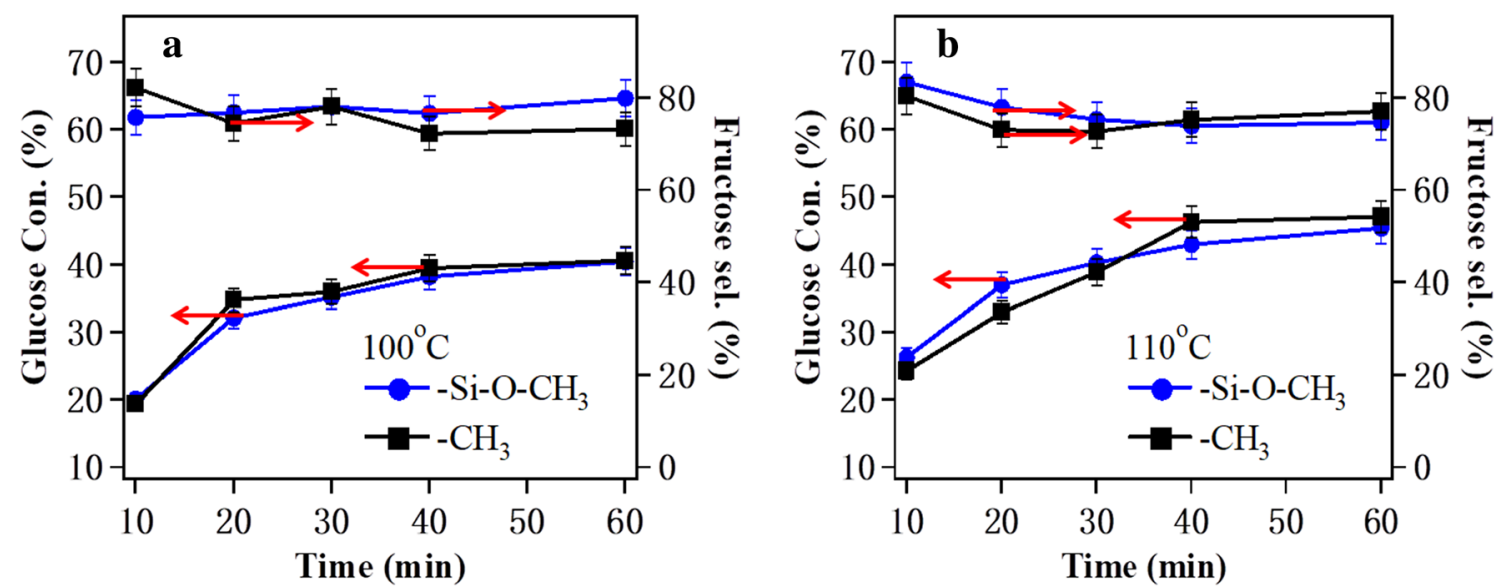

Fig. 5 Glucose conversion and fructose selectivity versus time profiles as a function of time under $\mathbf{a} 100$ and $\mathbf{b} 110^{\circ} \mathrm{C}$ for DMASi and BuNMe 2 . Reaction conditions: $0.5 \mathrm{~g}$ glucose, $5 \mathrm{~mL} \mathrm{H}{ }_{2} \mathrm{O}$, amine (mol\% relative to glucose), $10-60 \mathrm{~min}, 80-110{ }^{\circ} \mathrm{C}$<smiles>CCN</smiles><smiles>CCCCCCN</smiles><smiles>CCCCCCCCN</smiles>

Ethylamine

Hexylamine

Octlylamine

Fig. 6 The structure of aliphatic primary amine with 2, 6 and 8 alkyl chain

Table 2 Isomerization of glucose to fructose by aliphatic primary amine catalysts with different alkyl chain length

\begin{tabular}{lllll}
\hline Catalysts (alkyl chain length) & pKa & Glucose con. (\%) & Fructose yie. (\%) & Fructose sel. (\%) \\
\hline Ethylamine (2) & 10.70 & $38.85 \pm 1.9$ & $23.69 \pm 1.2$ & $60.98 \pm 2.8$ \\
Hexylamine (6) & 10.56 & $39.14 \pm 2.0$ & $24.34 \pm 1.2$ & $62.19 \pm 2.4$ \\
Octylamine (8) & 10.65 & $27.72 \pm 1.4$ & $19.38 \pm 0.9$ & $69.91 \pm 1.8$ \\
\hline
\end{tabular}

Reaction conditions: $0.5 \mathrm{~g}$ glucose, $5 \mathrm{~mL} \mathrm{H} 2 \mathrm{O}$, aliphatic primary amine catalyst (mol\% relative to glucose), $10 \mathrm{~min}, 110^{\circ} \mathrm{C}$

8 (octylamine), the glucose conversion dropped to 28\% with $\sim 70 \%$ fructose selectivity. The higher fructose selectivity can be explained by the fact that more glucose conversion lead to lower glucose conversion because of more acidic by-product generation as discussed above. As shown in Table 2, the three aliphatic primary amines are of close $\mathrm{pKa}$ values, all water-soluble and formed homogenous solutions. Thus, their $\mathrm{OH}^{-}$generation ability should not be very different, while ethylamine and hexylamine are significantly more active than octylamine. Thus the steric bulk is regarded as the main reason. In this work, we explain the difference by the fact that longer alkyl chain length leads to more flexibility, the chain may curl that weakens the amine catalytic effect.

In an industry producing process, the concentration of feedstock and catalyst loading is also important, which determines the target products' production capacity and cost. So the influence of initial hexylamine concentrations 
on the glucose conversion and fructose yield is evaluated in this part and the results are shown in Fig. 7.

Figure $7 \mathrm{a}$ shows an increase of the hexylamine dosage from 0.5 to $10 \mathrm{~mol} \%$, stable fructose selectivity (around $65 \%)$ fructose selectivity are obtained. More ethylamine leads to higher glucose conversion because of the more amine existence. While initial glucose concentration evaluation shows the glucose concentration varies from 0.1 to $0.5 \mathrm{~g}$ in $5 \mathrm{~mL} \mathrm{H}_{2} \mathrm{O}$, stable glucose conversion and fructose yield reached, and higher glucose initial concentration $\left(>0.5 \mathrm{~g}\right.$ in $5 \mathrm{~mL} \mathrm{H}_{2} \mathrm{O}$ ) resulted in a decrease in the glucose conversion due to the absence of enough catalysts. All above results demonstrate ethylamine can effectively catalyze the isomerization reaction under a variety of operational conditions.

As discussed above, the reaction condition (mainly residual time, temperature, initial glucose concentration and catalysts loadings) and whether being immobilized could affect the amine catalytic effects largely. Comparison of the adopted organosilanes amine and aliphatic primary amine in this work with representative homogeneous base catalysts is shown in Table 3.

As analyzed, for homogeneous base catalysts listed in Table 3, catalysts type and reaction conditions affect the glucose isomerization reaction. Different alkyl substituents also influence the glucose conversion and fructose selectivity. For our results, $45 \%$ of glucose conversion with $75 \%$ fructose selectivity could be obtained when DMASi acted as catalyst, which indicates DMASi is promising industrial homogenous catalyst for fructose production from glucose isomerization.

\section{Conclusions}

In the present work, three homogeneous amine type organosilanes (primary, secondary, and tertiary amine) were selected first as amine catalysts to screen their catalytic activity and kinetic toward glucose isomerization reaction. Results showed amine-generated $\mathrm{OH}^{-}$and amine itself played important roles in the isomerization reaction and organosilanes tertiary amine behaviors best. The generated acidic by-product not only causes the decrease of fructose selectivity but also reduced the glucose conversion kinetic. The substituent of siloxane $\left(-\mathrm{Si}-\mathrm{O}-\mathrm{CH}_{3}\right)$ with methyl $\left(-\mathrm{CH}_{3}\right)$ investigation showed in situ hydrolysis effect of $-\mathrm{Si}-\mathrm{O}-\mathrm{CH}_{3}$ group could be negligible, which provided guided significance for selecting amine-type homogeneous or grafted amine catalysts for the glucose isomerization reaction.

The substituent structure of amines on their isomerization performance was investigated by adopting aliphatic primary amine with different alkyl chain length. Higher alkyl chain resulted in lower glucose conversion for the alkyl chain curls that weaken the amine catalytic effect and hydration ability. Catalyst loadings and initial glucose concentration effects showed that hexylamine could effectively catalyze the isomerization reaction under a variety of operational conditions. This work will provide more details about amine catalysts on glucose isomerization into fructose and promote synthesis of platform chemicals in the biorenewable chemicals and fuel applications.
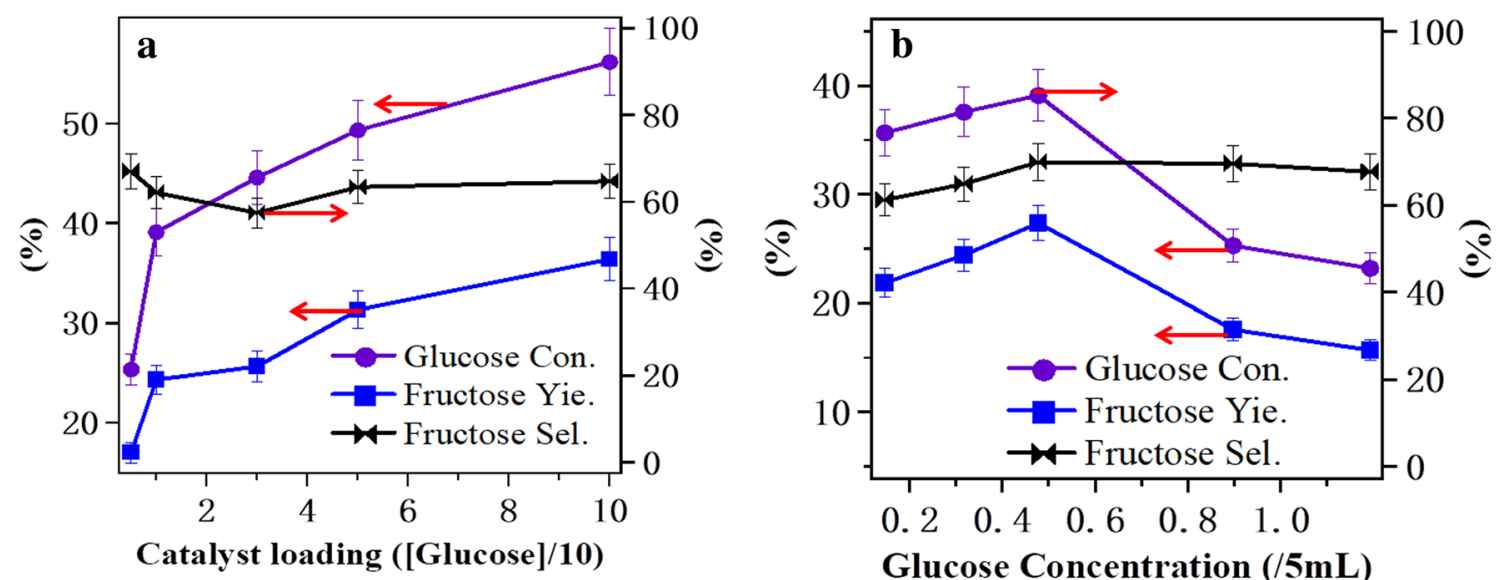

Fig. 7 Glucose conversion and fructose selectivity versus $\mathbf{a}$ hexylamine loading and $\mathbf{b}$ initial glucose concentration profiles under $110^{\circ} \mathrm{C}$ and $10 \mathrm{~min}$. Ethylamine loading are $0.5,1,35$ and 10 (mol\% relative to glucose); glucose concentrations are $0.1,0.3,0.5,0.9$ and $1.2 \mathrm{~g}$ in $5 \mathrm{~mL} \mathrm{H} \mathrm{H}_{2} \mathrm{O}$ 
Table 3 Isomerization of glucose to fructose with representative homogenous catalysts at different reactions conditions

\begin{tabular}{|c|c|c|c|c|c|}
\hline Catalysts (loading) & $\begin{array}{l}\text { Conditions (solvent, } \\
\text { temperature, time, glucose } \\
\text { concentration) }\end{array}$ & Glu conv. (\%) & Fru yie. (\%) & Fru sel. (\%) & Ref \\
\hline Triethylamine (10 mol\%) & $\mathrm{H}_{2} \mathrm{O}, 100{ }^{\circ} \mathrm{C}, 20 \mathrm{~min}, 10 \mathrm{wt} \%$ & 51 & 32 & 63 & Liu et al. (2014) \\
\hline Quinuclidine (10 mol\%) & $\mathrm{H}_{2} \mathrm{O}, 100^{\circ} \mathrm{C}, 2 \mathrm{~h}, 10$ wt $\%$ & 54 & 29 & 54 & Deshpande et al. (2019) \\
\hline Triethylamine (10 mol\%) & $\mathrm{H}_{2} \mathrm{O}, 100{ }^{\circ} \mathrm{C}, 2 \mathrm{~h}, 10 \mathrm{wt} \%$ & 48 & 27 & 56 & Deshpande et al. (2019) \\
\hline Diisopropylethylamine (10 mol\%) & $\mathrm{H}_{2} \mathrm{O}, 100{ }^{\circ} \mathrm{C}, 2 \mathrm{~h}, 10 \mathrm{wt} \%$ & 33 & 23 & 70 & Deshpande et al. (2019) \\
\hline Tri-n-propylamine (10 mol\%) & $\mathrm{H}_{2} \mathrm{O}, 100{ }^{\circ} \mathrm{C}, 2 \mathrm{~h}, 10 \mathrm{wt} \%$ & 12 & 9 & 75 & Deshpande et al. (2019) \\
\hline Imidazole (160 mol\%) & $\mathrm{H}_{2} \mathrm{O}, 120^{\circ} \mathrm{C}, 0.5 \mathrm{~h}, 10$ wt $\%$ & 60 & 33 & 55 & Yang et al. (2015) \\
\hline 1-(3-Aminopropyl) imidazole (7.5 mol\%) & $\mathrm{H}_{2} \mathrm{O}, 120^{\circ} \mathrm{C}, 0.5 \mathrm{~h}, 10 \mathrm{wt} \%$ & 47 & 20 & 43 & Yang et al. (2015) \\
\hline Tetramethylguanidine (3 mol\%) & $\mathrm{H}_{2} \mathrm{O}, 120^{\circ} \mathrm{C}, 0.5 \mathrm{~h}, 10 \mathrm{wt} \%$ & 59 & 30 & 51 & Yang et al. (2015) \\
\hline 1,5,7-Triazabicyclo[4.4.0]dec-5-ene (3 mol\%) & $\mathrm{H}_{2} \mathrm{O}, 120^{\circ} \mathrm{C}, 0.5 \mathrm{~h}, 10$ wt $\%$ & 64 & 32 & 50 & Yang et al. (2015) \\
\hline Trimethylamine (3 mol\%) & $\mathrm{H}_{2} \mathrm{O}, 100{ }^{\circ} \mathrm{C}, 0.5 \mathrm{~h}, 10$ wt $\%$ & 43 & 28 & 65 & Yang et al. (2015) \\
\hline Tris(2-aminoethyl)amine (3 mol\%) & $\mathrm{H}_{2} \mathrm{O}, 100{ }^{\circ} \mathrm{C}, 0.5 \mathrm{~h}, 10$ wt $\%$ & 43 & 24 & 56 & Yang et al. (2015) \\
\hline Polyethylenimine (0.5 mol\%) & $\mathrm{H}_{2} \mathrm{O}, 100{ }^{\circ} \mathrm{C}, 0.5 \mathrm{~h}, 10 \mathrm{wt} \%$ & 38 & 21 & 55 & Yang et al.(2015) \\
\hline Arginine (10 mol\%) & $\mathrm{H}_{2} \mathrm{O}, 120^{\circ} \mathrm{C}, 20 \mathrm{~min}, 10 \mathrm{wt} \%$ & 41 & 31 & 76 & Yang et al. (2016) \\
\hline Polyethylenimine (0.05 mol\%) & $\mathrm{H}_{2} \mathrm{O}, 110-120^{\circ} \mathrm{C}, 15 \mathrm{~min}, 10 \mathrm{wt} \%$ & $47-50$ & $33-36$ & $66-77$ & Yang and Runge (2016) \\
\hline Hexylamine (10 mol\%) & $\mathrm{H}_{2} \mathrm{O}, 110^{\circ} \mathrm{C}, 10 \mathrm{~min}, 10 \mathrm{wt} \%$ & 39 & 24 & 62 & This work \\
\hline APTES & $\mathrm{H}_{2} \mathrm{O}, 110{ }^{\circ} \mathrm{C}, 60 \mathrm{~min}, 10 \mathrm{wt} \%$ & 34 & 20 & 58 & This work \\
\hline APTMS & $\mathrm{H}_{2} \mathrm{O}, 110{ }^{\circ} \mathrm{C}, 60 \mathrm{~min}, 10 \mathrm{wt} \%$ & 50 & 31 & 61 & This work \\
\hline DMASi & $\mathrm{H}_{2} \mathrm{O}, 110^{\circ} \mathrm{C}, 60 \mathrm{~min}, 10 \mathrm{wt} \%$ & 45 & 34 & 75 & This work \\
\hline
\end{tabular}

Glu conv. glucose conversion, Fru yie. fructose yield, Fru sel. fructose selectivity

\section{Abbreviations}

5-HMF: 5-Hydroxymethylfurfural; FDCA: 2,5-Furandicarboxylic acid; API: 1-(3-Aminopropyl)imidazole; TMG: Tetramethylguanidine; TBD: 1,5,7-Triazabicyclo[4.4.0]dec-5-ene; DMASi: N,N-Dimethy1-3(trimethoxysily)propan-1-amine; APTMS: N-Methyl-3-(trimethoxysily)propan-1-amine; APTES: 3-(Trimethoxysily) propan-1-amine; BuNMe2: N,N-Dimethylbutylamine.

\section{Acknowledgements}

Not applicable.

\section{Authors' contributions}

$\mathrm{LZ}$ and $\mathrm{HZ}$ designed the study. $\mathrm{LZ}$ and $\mathrm{BD}$ performed the experiment and wrote a part of the manuscript. NL wrote a part of the manuscript and polished the manuscript. All authors read and approved the final manuscript.

\section{Funding}

This work has been financially supported by Research Foundation of China University of Petroleum-Beijing At Karamay (No. YJ2018B02006 and YJ2018B02007) and Scientific Research Program of Universities in Xinjiang Uygur Autonomous Region (XJEDU2019Y068 and XJEDU2019Y069).

\section{Availability of data and materials}

All data generated or analyzed during this study are included in this article.

\section{Ethics approval and consent to participate}

Not applicable.

\section{Consent for publication}

Not applicable.

\section{Competing interests}

The authors declare that they have no competing interests.

Received: 29 June 2019 Accepted: 9 September 2019

Published online: 17 September 2019

\section{References}

Carraher JM, Fleitman CN, Tessonnier J-P (2015) Kinetic and mechanistic study of glucose isomerization using homogeneous organic Brønsted base catalysts in water. ACS Catal 5:3162-3173

Corma A, Iborra S, Velty A (2007) Chemical routes for the transformation of biomass into chemicals. Chem Rev 107:2411-2502

de Bruijn JM, Kieboom APG, van Bekkum H (1986) Alkaline degradation of monosaccharides III. Influence of reaction parameters upon the final product composition. Recl Trav Chim Pays-Bas 105:176-183

Deshpande N, Pattanaik L, Whitaker MR, Yang C-T, Lin L-C, Brunelli NA (2017) Selectively converting glucose to fructose using immobilized tertiary amines. J Catal 353:205-210

Deshpande N, Cho EH, Spanos AP, Lin L-C, Brunelli NA (2019) Tuning molecular structure of tertiary amine catalysts for glucose isomerization. J Catal 372:119-127

Du M, Agrawal AM, Chakraborty S, Garibay SJ, Limvorapitux R, Choi B, Madrahimov ST, Nguyen ST (2019) Matching the activity of homogeneous sulfonic acids: the fructose-to-HMF conversion catalyzed by hierarchically porous sulfonic-acid-functionalized porous organic polymer (POP) catalysts. ACS Sustain Chem Eng 7:8126-8135

Gorbanev YY, Klitgaard SK, Woodley JM, Christensen CH, Riisager A (2009) Gold-catalyzed aerobic oxidation of 5-hydroxymethylfurfural in water at ambient temperature. Chemsuschem 2:672-675

Kim J-S, Lee Y-S (2008) Effect of reaction pH on enolization and racemization reactions of glucose and fructose on heating with amino acid enantiomers and formation of melanoidins as result of the Maillard reaction. Food Chem 108:582-592

Lam E, Luong JHT (2014) Carbon materials as catalyst supports and catalysts in the transformation of biomass to fuels and chemicals. ACS Catal 4:3393-3410

Lee HS, Hong J (2000) Kinetics of glucose isomerization to fructose by immobilized glucose isomerase: anomeric reactivity of D-glucose in kinetic model. J Biotechnol 84:145-153

Li H, Saravanamurugan S, Yang S, Riisager A (2016) Direct transformation of carbohydrates to the biofuel 5-ethoxymethylfurfural by solid acid catalysts. Green Chem 18:726-734 
Li B, Li L, Zhang Q, Weng W, Wan H (2017a) Attapulgite as natural catalyst for glucose isomerization to fructose in water. Catal Commun 99:20-24

Li H, Fang Z, Luo J, Yang S (2017b) Direct conversion of biomass components to the biofuel methyl levulinate catalyzed by acid-base bifunctional zirconia-zeolites. Appl Catal B 200:182-191

Li H, Yang S, Saravanamurugan S, Riisager A (2017c) Glucose isomerization by enzymes and chemo-catalysts: status and current advances. ACS Catal 7:3010-3029

Liu C, Carraher JM, Swedberg JL, Herndon CR, Fleitman CN, Tessonnier J-P (2014) Selective base-catalyzed isomerization of glucose to fructose. ACS Catal 4:4295-4298

Mika LT, Cséfalvay E, Németh Á (2018) Catalytic conversion of carbohydrates to initial platform chemicals: chemistry and sustainability. Chem Rev 118:505-613

Moliner M, Román-Leshkov Y, Davis ME (2010) Tin-containing zeolites are highly active catalysts for the isomerization of glucose in water. Proc Natl Acad Sci 107:6164

Morales-Leal FJ, Rivera de la Rosa J, Lucio-Ortiz CJ, De Haro-Del Rio DA, Solis Maldonado C, Wi S, Casabianca LB, Garcia CD (2019) Dehydration of fructose over thiol- and sulfonic-modified alumina in a continuous reactor for 5-HMF production: study of catalyst stability by NMR. Appl Catal B 244:250-261

Olson N, Deshpande N, Gunduz S, Ozkan US, Brunelli NA (2019) Utilizing imogolite nanotubes as a tunable catalytic material for the selective isomerization of glucose to fructose. Catal Today 323:69-75

Shaikh M, Singh SK, Khilari S, Sahu M, Ranganath KVS (2018) Graphene oxide as a sustainable metal and solvent free catalyst for dehydration of fructose to 5-HMF: a new and green protocol. Catal Commun 106:64-67

Shen F, Fu J, Zhang X, Qi X (2019) Crab shell-derived lotus rootlike porous carbon for high efficiency isomerization of glucose to fructose under mild conditions. ACS Sustain Chem Eng 7:4466-4472
Souza ROL, Fabiano DP, Feche C, Rataboul F, Cardoso D, Essayem N (2012) Glucose-fructose isomerisation promoted by basic hybrid catalysts. Catal Today 195:114-119

Xu J, Li K, Zhang L, Li H, Wang T (2019) SBA-15 supported organic base catalysts for highly effective isomerization of glucose to fructose. J Biobased Mater Bioenergy 13:739-747

Yabushita M, Shibayama N, Nakajima K, Fukuoka A (2019) Selective glucoseto-fructose isomerization in ethanol catalyzed by hydrotalcites. ACS Catal 9:2101-2109

Yang BY, Montgomery R (1996) Alkaline degradation of glucose: effect of initial concentration of reactants. Carbohydr Res 280:27-45

Yang Q, Runge T (2016) Polyethylenimines as homogeneous and heterogeneous catalysts for glucose isomerization. ACS Sustain Chem Eng 4:6951-6961

Yang Q, Zhou S, Runge T (2015) Magnetically separable base catalysts for isomerization of glucose to fructose. J Catal 330:474-484

Yang Q, Sherbahn M, Runge T (2016) Basic amino acids as green catalysts for isomerization of glucose to fructose in water. ACS Sustain Chem Eng $4: 3526-3534$

Zhang Z, Deng K (2015) Recent advances in the catalytic synthesis of 2,5-furandicarboxylic acid and its derivatives. ACS Catal 5:6529-6544

\section{Publisher's Note}

Springer Nature remains neutral with regard to jurisdictional claims in published maps and institutional affiliations.

\section{Submit your manuscript to a SpringerOpen ${ }^{\circ}$ journal and benefit from:}

- Convenient online submission

- Rigorous peer review

- Open access: articles freely available online

- High visibility within the field

- Retaining the copyright to your article

Submit your next manuscript at $\boldsymbol{\nabla}$ springeropen.com 